\title{
AUTORREGULACIÓN EMOCIONAL EN ADOLESCENTES
}

\author{
Gabriela Alejandra Salinas Peralta
}

\section{RESUMEN}

Este artículo muestra una revisión y hace reflexiones sobre autorregulación emocional durante la adolescencia en estudiantes de los primeros ciclos de instituciones educativas de nivel superior. Finalmente, se considera vital el acompañamiento de los padres e instituciones para facilitar el desarrollo de autorregulación emocional y para la prevención de problemas sociales, salud mental y deserción estudiantil.

\section{PALABRAS CLAVE}

Autorregulación, adolescencia, prevención, deserción estudiantil, problemas sociales y salud mental.

\section{ABSTRACT}

The present article shows a review and makes reflections on emotional self-regulation during adolescence in students of the first periods of higher education institutions. Finally, the presence of parents and institutions is considered vital to facilitate the development of emotional self-regulation and for the prevention of social problems, mental health and dropout.

\section{KEYWORDS}

Self-regulation, adolescence, prevention, dropout, social problems and mental health.
E n mi experiencia profesional como psicóloga en las diversas áreas de bienestar estudiantil en instituciones educativas de nivel superior como: Consultorio psicológico, Servicio de tutoría, Escuela de Líderes y Escuela de padres, he observado pobre manejo de autorregulación emocional en los estudiantes que pertenecen al grupo de adolescentes, sobre todo en los primeros ciclos, lo cual ocasiona comportamientos de riesgo y desadaptativos en la mayoría de ellos.

Los comportamientos de riesgo o desadaptativos pueden llegar a convertirseen delictivas (como se cita en Vizcardo 2015: 20), sino se brinda atención de las mismas en las edades tempranas de su aparición. La adolescencia se considera un periodo clave para el inicio e incremento del comportamiento antisocial; sin embargo, también es un momento elemental y propicio para la implementación de programas preventivos y reeducativos de comportamientos antisociales o delictivos (Vilariño et al. 2013).

Estos comportamientos derivan en problemas: emocionales, sociales y académicos, los mismos que son causales de deserción estudiantil, siendo un fenómeno que se acrecentó ciclo a ciclo, generando no solo pérdida de tiempo sino económico.

Es importante entender que la adolescencia es una etapa en el desarrollo del ser humano en el cual la persona tiende hacia el egocentrismo, ya que el adolescente se centra en sí mismo, busca una identidad propia dentro de la familia y la aprobación social de sus congéneres, además suele cuestionar ciertos principios sociales o morales, puesto que el desarrollo emocional y el desarrollo cognitivo no van en la misma sintonía. 
Entre otros factores que intervienen en la aparición de comportamientos agresivos podemos destacar (como se cita en Vizcardo 2015: 23), a la empatía y a la inteligencia emocional; los adolescentes que frecuentemente presentan conductas agresivas tienden a tener una falta en la habilidad para identificar y regular sus emociones negativas (López et al. 2009).

Existe preocupación en el mundo por la incidencia de la enfermedad mental en adolescentes (como se cita en Vizcardo 2015: 26), se estima que el $20 \%$ de los jóvenes presentan problemas de salud mental, con desórdenes de la ansiedad y depresión, contribuyendo al porcentaje de enfermos de entre los 12 y 18 años de edad (Costello, Egger \& Angold 2005).

De acuerdo con el Consorcio Internacional en Epidemiología Psiquiátrica (ICPE 2000), la mediana edad para el inicio de los desórdenes de la ansiedad, consumo de sustancias y problemas con el humor es entre los 15 y 26 años, esto a lo largo de varias ciudades de Europa, Norte América y Latino América. Los niveles elevados de estrés, también son detectados en esta etapa, los cuales tienden a asociarse a las patologías mentales (Grant et al. 2006).

En los últimos años se habla sobre la Inteligencia Emocional como reacción al enfoque de inteligencias cognitivas, ya que se primaba esta última sobre todo; sin embargo, hoy por hoy se busca que los estudiantes manejen ambas inteligencias para desarrollarse profesionalmente. Incluso en el campo laboral, se solicita dentro del perfil del postulante que logre controlar y manejar sus emociones en situaciones de conflicto.

Los adolescentes con mayor nivel emocional detectan mejor las presiones emocionales que puedan aparecer en clase o por parte de sus compañeros, son capaces de afrontar las diferencias entre sus propias emociones y las del resto de compañeros, al contrario de lo que ocurre con adolescentes que tienen menor control sobre sus emociones, por tanto, los primeros serán capaces de tener un autocontrol suficiente para no caer en las conductas autodestructivas como el consumo de alcohol, tabaco u otras sustancias (Trinidad y Johnson 2002, Fernández-Berrocal \& Ruiz 2008).

Surgen diversos autores que dan a conocer sobre Inteligencia Emocional como: Reuven Bar-On, Howard Gardner, John Mayer, Peter Salovey, Daniel Goleman, Bonano, entre otros, quienes dan vital importancia a la regulación de las propias emociones para manejarlas de forma adaptativa, puesto que la autorregulación emocional permite mantener constante el balance psicológico.

Trigoso (2013), afirma: "Concretamente, la revisión de la literatura científica actual, define tres modelos teóricos de IE, diferentes en sus planteamientos y componentes, que han recibido apoyo empírico y poseen sus propios instrumentos de evaluación estandarizados". Se divide estos tres modelos en dos grupos: los modelos mixtos y los modelos de habilidad (Cobb \& Mayer 2000). Dentro del modelo mixto se encuentran: Goleman y Bar-On; y dentro de los modelos de habilidad se encuentran: Mayer y Salovey.

Miguel de Pliego (2014), refiere: "Ante situaciones difíciles o amenazadoras, los procesos de regulación emocional comparten un objetivo funcional: minimizar la frecuencia, intensidad, duración o la ocurrencia de estados internos emocionales (p. ej.: miedo, ansiedad), sus pensamientos asociados y reacciones fisiológicas".

La regulación emocional (como se cita en Vizcardo 2015: 32), es la habilidad más compleja de la inteligencia emocional que se refiere a la habilidad para estar abierto a las emociones tanto positivas como negativas y poder reflexionar ante las mismas a fin de tomar decisiones regulando las emociones propias y ajenas, moderando las negativas e intensificando las positivas, abarca el manejo de nuestro 
mundo tanto intrapersonal como interpersonal (Fernández-Berrocal \& Extremera 2005).

Actualmente las instituciones educativas de nivel superior han observado estos problemas y han propuesto desde hace algunos años realizar un acompañamiento a su población estudiantil mediante: sesiones de orientación individual y grupal, talleres, charlas, cursos de desarrollo personal y eventos como actividades que buscan que el estudiante adolescente logre adaptarse a la vida estudiantil de nivel superior.

No olvidemos que la familia es pieza importante en el aprendizaje para autorregular emociones, porque desde que nacemos no proporcionan herramientas que favorecen la regulación emocional.

\section{REFERENCIAS}

Merlino, Aldo \& Ayllón, Silvia (2012). Experiencias en investigación educativa: deserción, regulación emocional y orientaciones en estudiantes universitarios. Argentina: Editorial Brujas.

Miguel De Priego Llerena, Wendy (2014). Ansiedad y autorregulación emocional en acogedores de Lima. Lima: Tesis para optar el título de Licenciada en Psicología con mención Clínica, UPCP.

Velásquez Centeno, Carlos M. (2003).
Inteligencia emocional y autoestima en estudiantes de la ciudad de Lima Metropolitana con y sin participación en actos violentos. Lima: Revista de Investigaciónen Psicología, Vol. 6, № 2 .

Vizcardo Jara, María Inés (2015). Inteligencia emocional y alteraciones del comportamiento en alumnos de 11 a 13 años de Arequipa. Lima: Tesis para optar el grado académico de Maestro en Psicología, USMP. 